\title{
Renal-Hepatic-Pancreatic Dysplasia: A Sibship With Skeletal and Central Nervous System Anomalies and NPHP3 Mutation
}

\author{
Lawrence Copelovitch, ${ }^{1 *}$ Maureen M. $0{ }^{\prime}$ Brien, ${ }^{2}$ Marta Guttenberg, ${ }^{3}$ Edgar A. Otto, ${ }^{4}$ \\ and Bernard S. Kaplan ${ }^{1}$
}

\author{
${ }^{1}$ Division of Nephrology, The Children's Hospital of Philadelphia, Philadelphia, Pennsylvania \\ ${ }^{2}$ Division of Oncology, Cincinnati Children's Hospital Medical Center, Cincinnati, Ohio \\ ${ }^{3}$ Department of Pathology, The Children's Hospital of Philadelphia, Philadelphia, Pennsylvania \\ ${ }^{4}$ Department of Pediatrics, University of Michigan, Ann Arbor, Michigan
}

Manuscript Received: 5 February 2013; Manuscript Accepted: 4 March 2013

\begin{abstract}
We report on five consecutive sibs three with fatal renal-hepaticpancreatic dysplastic (RHPD) syndrome and two pregnancies ending in early abortion. Three of the fetuses reached term and two survived for 15 and 58 days. They had diffusely cystic kidneys with absence of the distal collecting tubules, hepatic fibrosis, bile duct paucity, and pancreatic fibrosis with irregularly dilated ducts. These findings correspond to many of those reported by Ivemark et al. [Ivemark et al. (1959); Acta Paediat Scand 48: 1-11] as part of the RHPD syndrome. There are several notable differences in this family: one patient had hypocalvaria and a choroid plexus cyst at the right foramen of Luschka, multiple bone abnormalities including widened growth plates and abnormal development of the trabeculae of the ribs, "handle-bar" clavicles, wedge defects of the inferior margin of several thoracic vertebrae; the second patient had hypocalvaria and abnormally developed brain with bilateral exposure of the insulae; and a third patient had anencephaly. Mutational analysis of the two who survived beyond post-delivery demonstrated compound heterozygous novel frameshift mutations in the nephronophthisis type 3 gene (NPHP3). ๑ 2013 Wiley Periodicals, Inc.
\end{abstract}

Key words: renal-hepatic-pancreatic dysplasia; nephronophthisis; NPHP3; Ivemark syndrome

\section{INTRODUCTION}

Renal-hepatic-pancreatic dysplasia (RHPD) was described in sibs by Ivemark et al. [1959] but is now known to occur as a component of many other well-defined syndromes such as the Zellweger, Meckel, Jeune, Elejalde, and Saldino-Noonan chondrodysplasias, trisomies 9 and 13, and glutaric aciduria II [Ivemark et al., 1959; Hunter et al., 1991]. RHPD syndrome is an autosomal recessive trait and many patients present in utero with oligohydramnios. The kidneys may be dysplastic with peripheral cortical cysts, primitive collecting ducts, glomerular cysts, and metaplastic cartilage [Bernstein et al., 1987]. There is
How to Cite this Article:

Copelovitch L, O’Brien MM, Guttenberg

M, Otto EA, Kaplan BS. 2013. Renal-

hepatic-pancreatic dysplasia: a sibship with skeletal and central nervous system anomalies and nphp3 mutation.

Am J Med Genet Part A 161A:1743-1749.

fibrosis of liver and pancreas. Most patients die neonatally of respiratory insufficiency. RHPD is also known as Ivemark II syndrome and has been regarded as distinct from Ivemark I syndrome which comprises heterotaxy, poly- or asplenia and congenital cardiac anomalies. Recently, RHPD was determined to be caused by loss of NPHP3 gene function [Bergmann et al., 2008]. Skeletal and central nervous system (CNS) abnormalities were reported rarely, and anencephaly has not been reported in any documented case of RHPD or NPHP3 mutations. The purpose of this report is to broaden known range of RHPD due to NPHP3 mutations to include skeletal anomalies and anencephaly.

\footnotetext{
Abbreviations: CNS, central nervous system; ASD, atrial septal defect; PDA, patent ductus arteriosis; PFO, patent foramen ovale; $\mathrm{RVH}$, right ventricular hypertrophy

Conflict of interest: none.

*Correspondence to:

Lawrence Copelovitch, Division of Genetics, The Children's Hospital of Philadelphia, 34th St \& Civic Center Blvd, Philadelphia, PA 19104.

E-mail: copelovitch@email.chop.edu

Article first published online in Wiley Online Library

(wileyonlinelibrary.com): 17 May 2013

DOI 10.1002/ajmg.a.35958
} 


\section{CLINICAL REPORTS}

\section{Patient 1}

A male infant was born at 38 weeks gestation to a 27-year-old G2 P1 mother. Antenatal ultrasound examination at 20 weeks showed "polycystic" kidneys. Oligohydramnios was noted at a follow-up ultrasound examination and a tentative diagnosis was made of autosomal recessive polycystic kidney disease. The family history was negative for renal diseases or fetal or neonatal death and there was no history of consanguinity or prenatal exposure to alcohol, drugs, or medications including angiotensin-converting-enzyme inhibitors or non-steroidal anti-inflammatory drugs. The infant was born normally. Birth weight was $2.21 \mathrm{~kg}$; placenta and umbilical cord were normal. In the delivery room he was in severe respiratory distress and was intubated and mechanically ventilated. A chest radiograph showed severe pulmonary hypoplasia and a bellshaped rib cage. He had large anterior and posterior fontanelles, wide cranial sutures, Potter sequence, normal heart, abdomen, and male external genitalia. At $3 \mathrm{hr}$ of life the oxygen saturation acutely decreased from $100 \%$ to $20 \%$ and chest transillumination revealed a spontaneous left pneumothorax and a chest tube was inserted.

Laboratory studies showed normal serum electrolyte concentrations, BUN $9 \mathrm{mg} / \mathrm{dl}$, and serum creatinine concentration $0.9 \mathrm{mg} / \mathrm{dl}$. Results of cranial ultrasound examination were normal. A repeat chest radiograph showed fused vertebrae. During the first $12 \mathrm{hr}$ of life, he excreted $1 \mathrm{ml}$ of urine. He had hypotension, episodic oxygen desaturations, pulmonary hypertension and was treated with nitric oxide, dopamine, dobutamine, and epinephrine. Renal ultrasound studies revealed slightly enlarged kidneys (4.4 and $4.7 \mathrm{~cm}$ ), a $5 \mathrm{~mm}$ cyst in the right kidney, bilaterally increased echogenicity, lack of corticomedullary differentiation, a dilated left renal pelvis, and no urine in the bladder. On the 4 th day the serum creatinine concentration was $4.1 \mathrm{mg} / \mathrm{dl}$ and peritoneal dialysis was started. He had a persistent transfusion-dependent anemia that required multiple blood transfusions. The liver enzyme levels remained normal. On the 10th day a cranial ultrasound examination showed a parietal intraparenchymal hemorrhage in the right middle cerebral artery distribution. An electroencephalogram showed bilateral moderately severe encephalopathy. On day 15 , support was withdrawn with parental consent because of sepsis, a deteriorating clinical status, and severe pulmonary hypoplasia.

\section{Patient 2}

A stillborn anencephalic female was delivered at 42 weeks weighing $1.1 \mathrm{~kg}$.

\section{Patient 3}

A male infant was born at 36 weeks of gestation. A prenatal ultrasound study at 17 weeks of gestation showed bilateral renal cystic dysplasia and oligohydramnios. Due to the anomalies noted in the previous pregnancies a fetal MRI was performed at 22 weeks of gestation. It demonstrated large cystic kidneys and a very small amount of amniotic fluid. There was no history of prenatal exposure to alcohol, drugs, or medications.

Delivery was by elective cesarean because of the critically low amniotic fluid volume. Birth weight was $2.605 \mathrm{~kg}$. The placenta and umbilical cord were normal. He had severe respiratory distress and bradycardia and was intubated and mechanically ventilated. A chest radiograph documented small hypoplastic lungs with normal ribs and vertebrae. Results of a cranial ultrasound examination was normal. He remained persistently hypotensive, became acutely hypoxic, and a right-sided pneumothorax was diagnosed. A chest tube was inserted, and he was placed on an oscillating ventilator with nitric oxide infusion.

He had a large anterior fontanelle, wide cranial sutures, Potter sequence, and severe contractures. Heart, abdomen and genial examinations were normal. Initial serum concentrations were sodium $129 \mathrm{meq} / \mathrm{L}$, bicarbonate $13 \mathrm{meq} / \mathrm{L}$, calcium $6.2 \mathrm{meq} / \mathrm{L}$; serum creatinine $1.3 \mathrm{mg} / \mathrm{dl}$ and BUN $21 \mathrm{mg} / \mathrm{dl}$. An abdominal ultrasound study showed a normal-sized liver with no intrahepatic ductal dilation, a $1 \mathrm{~cm} \times 9 \mathrm{~cm}$ right hepatic lobe cyst, and an enlarged $4 \mathrm{~mm}$ common bile duct. The pancreas was normal-sized $(1.1 \mathrm{~cm} \times 0.9 \mathrm{~cm} \times 0.8 \mathrm{~cm})$ without cysts. Persistent anuria caused progressive anasarca. The pulmonary edema rendered him more difficult to oxygenate. Peritoneal dialysis (PD) was started on the 11th day.

The cardio-respiratory instability and hypotension persisted over the next 2 months. The course was complicated by: recurrent pneumothoraces, pulmonary hypertension, marked right ventricular hypertrophy and dilation, a moderate patent foramen ovalum with bi-directional flow, a small patent ductus with right-to-left shunting, and transfusion-dependent anemia. There was severe hepatic dysfunction with persistent hypoalbuminemia and direct hyperbilirubinemia but the liver enzyme levels remained normal. Evidence of pancreatic dysfunction appeared on the 39th day and an insulin infusion was initiated to treat hyperglycemia, which eventually resolved over 6 days. The peritoneal dialysis was complicated by leakage and infection with coagulase-negative Staphylococcus. He had a leukemoid-like reaction with a white blood cell count as high as 80,000 cells/cm (60\% segmented neutrophils, $14 \%$ bands, $10 \%$ metamyelocytes, $1 \%$ myelocytes). The white blood cell count gradually normalized over several weeks. On the 57 th day he began to have multiple desaturations that resulted in a prolonged bradycardic and hypotensive episode. A chest roentgenogram at that time showed complete right upper lobe atelectasis. The patient recovered from the cardiopulmonary arrest after vigorous manual ventilation. On the 58th day the parents elected to withdraw ventilatory support.

\section{Family History}

The mother had had two miscarriages. One fetus died in utero at 10 weeks. The chromosomes of this fetus were normal. The second fetus died at 15 weeks in utero and had enlarged kidneys at 14 1/2 weeks. Over the last 12 weeks of gestation, the mother was given nine intra-amniotic normal saline infusions. During one of the infusions the umbilical cord was punctured accidentally and cells were obtained for chromosomal analysis; this showed a normal 46, XY karyotype.

\section{Pathology}

Patient 1. The anterior fontanelle measured $4 \mathrm{~cm} \times 3 \mathrm{~cm}$ and the posterior fontanelle $3 \mathrm{~cm} \times 3 \mathrm{~cm}$. The sagittal, metopic, and 
lambdoidal sutures averaged $1 \mathrm{~cm}$ in width. The calvarial bones were present as irregular islands of ossification with irregularly jagged or feathered edges and the skull was mainly membranous fontanelle. There was clinodactyly of the fifth fingers. Rib sections showed widening of the growth plate with retention of trabecular cartilage core for many centimeters. Additional skeletal abnormalities included "handle-bar" clavicles, short ribs, and wedge defects of the inferior margin of several thoracic vertebrae.

The total of the kidneys was $22.5 \mathrm{~g}$ (normal $=27 \mathrm{~g}$ ). The left ureteropelvic junction was obstructed and the parenchyma of both kidneys was diffusely cystic. Microscopic examination showed no normal distal collecting tubules and extensive fibrosis and focal calcifications. The distal tubules were immature and surrounded by mesenchyme. There were scattered cystically dilated ducts and several larger centrally located cysts in the left kidney. The bladder was small, thick-walled, contracted, and empty.

The fetus had a choledochal cyst, obstruction of the ampulla of Vater, extensive hepatocellular and canalicular bile stasis, and fewer than one bile duct per portal tract. There was extensive interstitial fibrosis of the pancreas with dilated, irregular ducts, chronic inflammation and small areas of normal pancreatic tissue. Islet cells could be only identified by immunohistochemical staining. The bone marrow contained mainly myeloid precursors and megakaryocytes and was markedly deficient in erythroid precursors. Also there was a right parietal hemorrhagic infarct and a choroid plexus cyst at the right foramen of Luschka.

Patient 2. The baby was anencephalic. Heart, lungs, liver, spleen stomach, and small and large intestines were grossly normal. There were no adrenal glands. Each kidney weighed $11 \mathrm{~g}$ and, on cut section there were minute cysts up to $0.2 \mathrm{~cm}$ in size. The liver was markedly congested on cut section. Histological sections of the liver and kidney were not available. The pancreas was grossly normal but histological sections demonstrated areas of interstitial fibrosis with dilated, irregular ducts, and chronic inflammation.

Patient 3. The anterior fontanelle was large with an open metopic suture. There was a hypocalvarial skull with "feathered" small skull bones. Growth plates were well-organized and normally developed.

Both kidneys were normally positioned within the retroperitoneum, enlarged and diffusely cystic without any recognizable normal parenchyma. The cysts ranged in size from $<0.1$ to $0.5-$ $1.0 \mathrm{~cm}$.

The collecting system was abnormally developed and both ureters were atretic before they reached the pelvis. The seminal vesicles were abnormally developed. The testes were small and incompletely descended (left in inguinal canal, right in upper scrotum). The epididymides were immature and detached from the testes.

The liver showed sinusoidal congestion and portal and sinusoidal fibrosis. The common bile duct was blind-ending with a dilated extrahepatic biliary tree. There was marked hepatocellular and canalicular cholestasis and hematopoietic activity throughout the liver. Many small portal tracts only contained small peripheral ductules and interlobular ducts were absent as demonstrated by immunostaining for cytokeratin 7 . Sections of a $1.0 \mathrm{~cm}$ right hepatic lobe cyst reveal a cavity lined by biliary epithelium. There was pancreatic fibrosis, which in some areas almost completely replaced the exocrine elements. Many ducts were dilated and within the areas of fibrosis displayed irregular configurations similar to that seen in biliary dysgenesis of the liver.

The bone marrow was normocellular. Although there was trilineage hematopoiesis, there were numerous histiocytes with evidence of hematophagocytosis, confirmed by CD163 immunostaining.

On gross examination the brain was abnormally developed (weight $379 \mathrm{~g}$, expected $506 \mathrm{~g}$ ) with bilateral exposure of the insulae. Microscopic examination was not performed.

\section{Mutational Analysis}

We performed mutation analysis of all known NPHP genes (NPHP1, INVS, NPHP3, NPHP4, IQCB1, CEP290, GLIS2, RPGRIP1L, NEK8, SDCCAG8, TMEM67, TTC21B, and WDR19) by applying a novel high-throughput sequencing technique described elsewhere [Halbritter et al., 2012]. In brief, we performed PCR-based 48.48 Access Array microfluidic technology (Fluidigm) with consecutive next generation sequencing. We applied a primer multiplexing approach allowing PCR-based amplification of all exons for 48 DNA samples simultaneously in all 13 known NPHP genes (NPHP1-13). After amplification followed by indexing of all patient-derived products with different $10 \mathrm{bp}$-barcodes in a subsequent PCR, $2 \times 150$ paired-end sequencing was performed on a GAIIx instrument (Illumina). Bioinformatics analysis was conducted using CLC-Genomics-Workbench software.

Mutational analysis in Patient 3 uncovered two novel heterozygous frameshift mutations in the NPHP3 gene (c.1206delA, p. Val403Serfs ${ }^{*}$; c.3003delT, Phe1001Leufs*61). After isolating DNA from a FFPE-kidney tissue block from Patient 1, we performed segregation analysis using standard Sanger sequencing. Patient 1 carries both heterozygous NPHP3 mutations as does his sib (Patient 3), whereas both parents carry only one heterozygous NPHP3 mutation. The mother carries the p.Val403Serfs ${ }^{*} 9$ and the father the p.Phe1001Leufs*61 frameshift mutation. No additional mutations were found in any of the other 12 NPHP genes investigated by high-throughput mutation analysis. Tissue was not available for genetic testing on the anencephalic stillborn or the two miscarriages however the presence renal cysts and pancreatic abnormalities in the stillborn suggests that the same NPHP3 mutations were present.

\section{DISCUSSION}

The triad of renal-hepatic-pancreatic dysplasia, described by Ivemark et al. [1959] typically includes cystic kidney disease with fibrosis of the liver and pancreas. The renal lesions in 18 cases of non-syndromal renal-hepatic-pancreatic dysplasia [Larson et al., 1995] were characterized by disorganized parenchyma and dilated immature ducts surrounded by fibromuscular collars in loose undifferentiated mesenchyme, and were similar to the findings in our patients. Pancreatic findings [Larson et al., 1995] included duct ectasia, acinar hypoplasia, and fibrosis consistent with the severe pancreatic dysplasia and fibrosis in our patients [Larson et al., 1995]. Findings in the liver of our patients were notable for extrahepatic duct obstruction, choledochal cyst, hepatic lobe cyst, severe bile stasis, and lack of bile ducts. Most of the 
originally described cases of RHPD had bile duct proliferation and portal fibrosis as opposed to paucity. Recently, two sibs were reported with RHPD and NPHP3 mutations; bile duct paucity, portal fibrosis, and persistence of embryonic bile duct structures in the ductal plate [Fiskerstrand et al., 2010]. Bile duct proliferation has been noted in several of the ciliopathies and is commonly observed in Meckel syndrome which is phenotypically similar to RHPD and can also be caused by mutations in the NPHP3 gene [Bergmann et al., 2008]. The hepatic changes are the most variable aspect of RHPD and range from minor portal expansion to bile duct dysgenesis [Larson et al., 1995]. Additionally, two of the four cases reported by Larson et al. had common bile duct cysts which may be similar to the choledochal cyst and right hepatic lobe cyst noted in our patients.

Ciliopathy describes a group of genetic conditions whose pathogenesis results from defective cilia. A number of syndromes that had been previously loosely associated with shared clinical features are now grouped under this rubric. Patients these syndromes have renal cystic and hepatobiliary disease, some have laterality defects and retinal degeneration and some have had polydactyly. The ciliopathies include autosomal recessive and dominant polycystic kidney disease, nephronophthisis, the Meckel, Bardet-Biedl, Joubert, Senior-Loken, Jeune, oro-facial-digital type 1, Ellis-van Creveld, Sensenbrenner, Alstrom syndromes, and Leber congenital amaurosis.

Nephronophthisis is a group of autosomal recessive cystic kidney diseases ranging from lethality in utero to adult-onset of previously clinically undetected disease. Patients with nephronophthisis present with progressive renal failure. At least seventeen different NPHP genes (NPHP1-15, AHI1, and CC2D2A) have been determined [Chaki et al., 2011]. It is now apparent that there may be considerable phenotypic overlap resulting from mutations of the different NPHP genes as well as genes associated with the other ciliopathies. For example, mutations in the NPHP6 gene were reported in patients with the nephronophthisis complex, Meckel syndrome, Bardet-Biedl syndrome, Joubert syndrome, and Senior-Loken syndrome [Baala et al., 2007; Helou et al., 2007; Leitch et al., 2008]. Variable expression within and among families further complicated traditional classifications. Furthermore, apparently comparable or even identical mutations in the same gene cause very different phenotypes.

Bergmann et al. [2008] first described two families with RHPD associated with loss of NPHP3 function and also described two other families with homozygous mutations in the NPHP3 gene with different clinical phenotypes. One couple had two children with Meckel syndrome and the other a child with glomerulocystic kidney disease, congenital hepatic fibrosis, situs inversus, post-axial polydactyly, and preauricular fistula. They also described hypomorphic mutations in the NPHP3 gene associated with either isolated adolescent-type nephronophthisis, nephronophthisis associated hepatic fibrosis, or Senior-Loken syndrome [Olbrich et al., 2003]. More recent studies of families with NPHP3 mutations have also shown that CNS abnormalities (cerebellar vermis aplasia, polymicrogyria, molar tooth sign, intellectual disability), cardiac anomalies (atrial septal defect, ventricular septal defects, pulmonary valve stenosis), and situs inversus are not uncommon [Simpson et al., 2009; Fiskerstrand et al., 2010; Chaki et al., 2011]. It is now clear that NPHP3 mutations can cause a broad range of early embryonic patterning defects resulting in phenotypic overlap of several of the previously described clinical syndromes. Tables I and II summarize the clinical findings and genetic mutations that have currently been observed with NPHP3 mutation associated RHPD.

Skeletal abnormalities are a major manifestation of several of the ciliopathies including Jeune syndrome (short ribs, hypoplastic iliac wings, "trident" acetabular roofs, and rhizomelic limb shorteness), Bardet-Biedl syndrome (post-axial polydactyly and brachydactyly), Ellis van Creveld (short limbs, short ribs, and post-axial polydactyly), and oro-facial-digital syndrome but have been rarely reported in association with RHPD. Balci et al. [Balci et al., 1999, 2000] described three children with cystic dysplasia of the kidney and pancreas (without hepatic fibrosis or cysts), situs inversus totalis, and bowing of the lower limbs and clavicles. Of note, our Patient 1 had "handle-bar" clavicles. Alessandri et al. [2009] described two children with renal cystic dysplasia, paucity of bile ducts, situs inversus, and bowing of the femora. As a result of the RHPD-like phenotype NPHP3 mutational analysis was performed but did not uncover any abnormalities. This once again highlights the considerable phenotypic overlap observed in what is most likely a yet undetected mutation within the ciliopathy spectrum. Bergmann et al. [2008] described two sibs with homozygous NPHP3 mutations and the associated RHPD phenotype from Cameroon. One of the sibs had extremely large fontanelles and hypocalvaria. To our knowledge this is the only other report of hypocalvaria in RHPD due to NPHP3 mutations.

Specific CNS abnormalities including cerebellar vermis hypoplasia or agenesis (Joubert syndrome, Bardet-Biedl syndrome), encephalocele (Meckel syndrome, Joubert syndrome), agenesis of the corpus callosum (oro-facial-digital syndrome), and cystic brain lesions (oro-facial-digital syndrome) occur in several of the ciliopathies although not typically in RHPD. More recently it has also been recognized that NPHP3 mutations can also be associated with a variety of CNS abnormalities including cerebellar vermis aplasia, polymicrogyia, molar tooth sign, and intellectual disability [Simpson et al., 2009; Fiskerstrand et al., 2010; Chaki et al., 2011]. To our knowledge, this is the first report of anencephaly in RHPD or associated with NPHP3 mutations. It is also noteworthy that [Bergmann et al., 2008] described a child with homozygous NPHP3 mutations and the associated RHPD phenotype from Cameroon with a cyst on the floor of the right ventricle and bilateral choroid plexus cysts. Patient 1 in our sibship also had a choroid plexus cyst at the right foramen of Luschka. In addition, Patient 3 in our sibship also had CNS structural abnormalities with a poorly developed brain and bilateral exposure of the insulae. Similar CNS findings were described in a child with NPHP3 mutation associated RHPD and polymicrogyria [Fiskerstrand et al., 2010].

The questions whether heterotaxy-spectrum cardiovascular disorders (Ivemark I) and RHPD (Ivemark II) are always separate entities is not entirely clear. The majority of heterotaxy cases are still idiopathic but mutations have been identified in more than 15 genes in individuals with heterotaxy or heterotaxyspectrum congenital heart disease. These mutations likely ac- 
TABLE I. Renal, Hepatic, and Pancreatic Findings in NPHP3 Mutation Associated Renal-Hepatic-Pancreatic-Dysplasia

\begin{tabular}{|c|c|c|c|c|}
\hline & NPHP3 mutations & Renal & Hepatic & Pancreatic \\
\hline Fiskerstrand et al. [2010] & Homozygous: c.2694-2_2694-1delAG & Small & Bile duct paucity & Enlarged \\
\hline Patient 1 & $\begin{array}{c}\text { Deletion of splice acceptor resulting in } \\
\text { premature stop codon }\end{array}$ & Cystic dysplastic & Portal fibrosis & Fibrosis \\
\hline Fiskerstrand et al. [2010] & Homozygous: c.2694-2_2694-1deIAG & Enlarged & Bile duct paucity & Dysplasia \\
\hline Patient 2 & $\begin{array}{c}\text { Deletion of splice acceptor resulting in } \\
\text { premature stop codon }\end{array}$ & Cystic dysplastic & $\begin{array}{l}\text { Abnormally branched } \\
\text { medium-size bile ducts }\end{array}$ & Dysplastic ducts \\
\hline Bergmann et al. [2008] & Homozygous: & Enlarged & Cysts & Unknown \\
\hline Patient 1 & $\begin{array}{l}\text { c. } 1729 C \text { to } T \\
\text { p.Arg5?7X }\end{array}$ & Multicystic dysplastic & & \\
\hline Bergmann et al. [2008] & Homozygous: & Enlarged & Ductal plate malformation & Cystic \\
\hline Patient 2 & $\begin{array}{l}\text { c. } 1729 C \text { to } \mathrm{T} \\
\text { p.Arg5?7X }\end{array}$ & Multicystic dysplastic & & \\
\hline Bergmann et al. [2008] & Heterozygous: & & Ductal plate malformation & Normal \\
\hline Patient 3 & $\begin{array}{l}\text { c. } 2918 \mathrm{G} \text { to } A \\
\text { p.Arg973GIn } \\
\text { c. } 3340 \text { C to T } \\
\text { p.GIn1114X }\end{array}$ & Multicystic dysplastic & & \\
\hline $\begin{array}{l}\text { Bergmann et al. [2008] } \\
\text { Patient } 4\end{array}$ & $\begin{array}{l}\text { Heterozygous: } \\
\text { c. } 2918 \mathrm{G} \text { to A } \\
\text { p.Arg973GIn } \\
\text { c. } 3340 \mathrm{C} \text { to } \mathrm{T} \\
\text { p.GIn1114X }\end{array}$ & Multicystic dysplastic & Ductal plate malformation & $\begin{array}{l}\text { Increased } \\
\text { echogenicity }\end{array}$ \\
\hline Copelovitch et al. [2013] & Heterozygous: & Cystic dysplastic & Bile duct paucity & Fibrosis \\
\hline Patient 1 & $\begin{array}{l}\text { c. } 1206 \text { delA p.Val403Serfs }{ }^{*} 9 \\
\text { c. } 3003 \text { delT Phe1001Leufs }{ }^{*} 61\end{array}$ & & Choledochal cyst & $\begin{array}{l}\text { Dilated irregular } \\
\text { ducts }\end{array}$ \\
\hline Copelovitch et al. [2013] & Likely & Cysts & Congestion & Fibrosis \\
\hline Patient 2 & $\begin{array}{c}\text { Heterozygous: } \\
\text { c.1206delA p.Val403Serfs }{ }^{*} 9 \\
\text { c.3003delT Phe1001Leufs }{ }^{*} 61\end{array}$ & & & $\begin{array}{l}\text { Dilated irregular } \\
\text { ducts }\end{array}$ \\
\hline Copelovitch et al. [2013] & Heterozygous: & Enlarged & Bile duct paucity & Fibrosis \\
\hline Patient 3 & $\begin{array}{l}\text { c.1206delA p.Val403Serfs }{ }^{*} 9 \\
\text { c. } 3003 \text { delT Phe1001Leufs }{ }^{*} 61\end{array}$ & Cystic dysplastic & $\begin{array}{c}\text { Portal } \\
\text { Fibrosis } \\
\text { Hepatic lobe cyst } \\
\text { Enlarged common bile } \\
\text { duct }\end{array}$ & $\begin{array}{l}\text { Dilated irregular } \\
\text { ducts }\end{array}$ \\
\hline
\end{tabular}

count for approximately $15 \%$ of heterotaxy-spectrum disorders [Tariq et al., 2011]. Situs inversus and congenital cardiac abnormalities (atrial septal defect, ventricular septal defects, pulmonary valve stenosis, aortic coarctation) also occur in patients with mutations in the NPHP2 and NPHP3 genes [Chaki et al., 2011]. In addition, several other ciliopathy-related clinical phenotypes were previously associated with both situs inversus (Meckel syndrome, Bardet-Biedl syndrome, Joubert syndrome) and congenital cardiac defects (Bardet-Biedl syndrome, Ellis-van Creveld syndrome).

An early report of RPHD described a brother and sister who both died within $24 \mathrm{hr}$ of birth with enlarged polycystic kidneys [Crawfurd, 1978]. Both children had cystic renal dysplasia. The pancreas was enlarged, nodular, and cystic in both children. Liver histology of one infant showed portal fibrosis with bile duct proliferation. In addition, one had cardiac transposition and asplenia and the other had hypoplasia of the spleen. In five patients with RHPD, two had findings of Ivemark I: one patient had polysplenia and another had situs inversus without cardiac defects [Bernstein et al., 1987]. A more recent report from Croatia [Krzelj et al., 2000] describes a newborn infant with aspects of Ivemark I syndrome and cystic renal dysplasia: there was dextrocardia, transposition of the great vessels, stenosis of the pulmonary artery, common atrioventricular canal, patent ductus arteriosus, asplenia, and cystic dilated collecting ducts of the kidney. In addition there are several reports of Ivemark I syndrome associated with pancreatic abnormalities including pancreatic agenesis [Konstantinidou et al., 2008] and a congenital pancreatic cyst [Chahed et al., 2012]. Whether a subset of patients with heterotaxy-spectrum cardiovascular disorders (Ivemark I) are caused by mutations in the spectrum of ciliopathies remains to be determined.

In summary, we report on a sibship with a compound heterozygote mutation in NPHP3 and an RHPD phenotype. This sibship extends the known phenotype of NPHP3 mutation caused RHPD to include skeletal and CNS anomalies, specifically anencephaly. 
TABLE II. Central Nervous System, Cardiac, and Skeletal Findings in NPHP3 Mutation Associated Renal-Hepatic-Pancreatic-Dysplasia

\author{
Fiskerstrand et al. [2010] \\ Patient 1 \\ Fiskerstrand et al. [2010] \\ Patient 2
}

Bergmann et al. [2008]

Patient 1

Bergmann et al. [2008]

Patient 2

Bergmann et al. [2008]

Patient 3

Bergmann et al. [2008]

Patient 4

Copelovitch et al. [2013]

Patient 1

\author{
CNS \\ Normal \\ Triangular configuration of \\ lateral ventricles \\ Polymicorgyria of the \\ cingulated gyri \\ Cyst in right ventricle \\ Bilateral choroid plexus cyst \\ Normal \\ Unknown \\ Normal
}

Choroid plexus cyst

Patient 2

Copelovitch et al. [2013]

Patient 3

\author{
Anencephaly \\ Poorly developed brain with \\ bilateral exposure of the insulae
}

\section{Cardiac \\ Normal}

Dextroposition

Situs inversus

No

Yes

Skeletal

Normal

Normal

ASD, PDA
RVH
PDA

Nodular dysplasia

of valves

Normal

Normal

Normal

No

No

No

No

No

o

\section{Hypocalvaria \\ Large Fontanelles Wide cranial sutures Widened growth plates Abnormal development of the trabeculae of the ribs Handle-bar clavicles Wedge defects of the thoracic vertebrae} Normal No Unknown

PFO, PDA No $\mathrm{RVH}$
Hypocalvaria

Large fontanelles

\section{REFERENCES}

Alessandri JL, Cartault F, Brayer C, Cuillier F, Riviere JP, Ramful D, Gubler MC. 2009. Renal cystic dysplasia, paucity of bile ducts, situs inversus, bowing of the femora in two siblings in the Reunion Islands: A ciliopathy? Clin Dysmorphol 18:209-212.

Baala L, Audollent S, Martinovic J, Ozilou C, Babron MC, Sivanandamoorthy S, Saunier S, Salomon R, Gonzales M, Rattenberry E, Esculpavit C, Toutain A, Moraine C, Parent P, Marcorelles P, Dauge MC, Roume J, Le Merrer M, Meiner V, Meir K, Menez F, Beaufrere AM, Francannet C, Tantau J, Sinico M, Dumez Y, MacDonald F, Munnich A, Lyonnet S, Gubler MC, Genin E, Johnson CA, Vekemans M, Encha-Razavi F, AttieBitach T. 2007. Pleiotropic effects of CEP290 (NPHP6) mutations extend to Meckel Syndrome. Am J Hum Genet 81:170-179.

Balci S, Bostanoglu S, Altinok G, Ozaltin F. 1999. Sibs diagnosed prenatally with situs inversus totalis, renal and pancreatic dysplasia, and cysts: A new syndrome? Am J Med Genet 82:166-169.

Balci S, Bostanoglu S, Altinok G, Ozaltin F. 2000. New syndrome? Three siblings diagnosed prenatally with situs inversus totalis, renal and pancreatic dysplasia, and cysts. Am J Med Genet 90:185-187.

Bergmann C, Fliegauf M, Ortiz N, FrankV, Olbrich H, Kirschner J, Schermer B, Schmedding I, Kispert A, Kranzlin B, Nurnberg G, Becker C, Grimm T, Girschick G, Lynch SA, Kelehan P, Senderek J, Neuhaus TJ, Stallmach T, Zentgraf H, Nurnberg P, Gretz N, Lo C, Lienkamp S, Schafer T, Walz G, Benzing T, Zerres K, Omran H. 2008. Loss of Nephrocystin-3 function can cause embryonic lethality, Meckel-Gruber-like syndrome, Situs inversus, and renal-hepatic pancreatic dysplasia. Am J Hum Genet 82:959-970.

Bernstein J, Chandra M, Creswell J, Kahn E, Malouf NN, McVicar M, Weinberg AG, Wybel RE. 1987. Renal-hepatic-pancreatic dysplasia: A syndrome reconsidered. Am J Med Genet 26:391-403.

Chahed A, Mokki M, Aloui S, Hidouri S, Ksia A, Krichene I, Maazoun K, Sahnoun L, Belghith M, Salem R, Njim L, Nouri A. 2012. Congenital pancreatic cyst with Ivemark II syndrome: A rare case. J Pediatr Surg 47: E33-E36.

Chaki M, Hoefele J, Allen SJ, Ramaswami G, Janssen S, Bergmann C, Heckenlively JR, Otto EA, Hildebrandt F. 2011. Genotype-phenotype correlation in 440 patients with NPHP-related ciliopathies. Kid Int 80:1239-1245.

Crawfurd MD. 1978. Renal dysplasia and asplenia in two sibs. Clin Genet 14:338-344.

Fiskerstrand T, Houge G, Sund S, Scheie D, Leh S, Boman H, Knappskog PM. 2010. Identification of a gene for renal-hepaticpancreatic dysplasia by microarray-based homozygosity mapping. J Mol Diagn 12:125-131.

Halbritter J, Diaz K, Chaki M, Porath JD, Tarrier B, Fu C, Innis JL, Allen SJ, Lyons RH, Stefanidis CJ, Omran H, Soliman NA, Otto EA. 2012. Highthroughput mutation analysis in patients with a nephronophthisis associated ciliopathy applying multiplexed barcoded array-based PCR. J Med Genet 49:756-767. 
Helou J, Otto EA, Attanasio M, Allen SJ, Parisi MA, Glass I, Utsch B, Hashmi S, Fazzi E, Omran H, O’Toole JF, Sayer JA, Hildebrandt F. 2007. Mutation analysis of NPHP6/CEP290 in patients with Joubert syndrome and Senior-Loken syndrome. J Med Genet 44:657-663.

Hunter AGW, Jimenez C, Tawagi FGR. 1991. Familial renal-hepaticpancreatic dysplasia and Dandy-Walker cyst: A distinct syndrome? Am J Med Genet 41:201-207.

Ivemark BI, Oldfelt V, Zetterstrom R. 1959. Familial dysplasia of the kidneys, liver, and pancreas. A probably genetically determined syndrome. Acta Paediat Scand 48:1-11.

Konstantinidou A, Sifakis S, Koukoura O, Mantas N, Agrogiannis G, Patsouris E. 2008. Pancreatic aplasia in a fetus with asplenia-cardiovascular defect-heterotaxy (Ivemark Syndrome). Birth Defects Res (Part A) $82: 602-604$

Krzelj V, Kragic I, Glavina-Durdov M, Jakl R, Bucat M, Kuzmic-Pruzac I. 2000. Ivemark syndrome: Asplenia with kidney collecting duct cysts and polysplenia with cerebellar cysts. Turk J Pediatr 42:234-238.
Larson RS, Rudloff MA, Liapis H, Manes JL, Davila R, Kissane J. 1995. The Ivemark syndrome: Prenatal diagnosis of an uncommon cystic renal lesion with heterogeneous associations. Pediatr Nephrol 9:594-598.

Leitch CC, Zaghloul NA, Davis EE, Stoetzel C, Diaz-Font A, Rix S, Alfadhel M, Lewis RA, Eyaid W, Banin E, Dollfus H, Beales PL, Badano JL, Katsanis N. 2008. Hypomorphic mutations in syndromic encephalocele genes are associated with Bardet-Biedl syndrome. Nat Genet 40:443-448.

Olbrich H, Fliegauf M, Hoefele J, Kispert A, Otto E, Volz A, Wolf MT, Sasmaz G, Trauer U, Reinhardt R, Sudbrak R, Antignac C, Gretz N, Walz G, Schermer B, Benzing T, Hildebrandt F, Omran H. 2003. Mutations in a novel gene, NPHP3, causes adolescent nephronopthisis, tapeto-retinal degeneration and hepatic fibrosis. Nat Genet 34:455-459.

Simpson MA, Cross HE, Cross L, Helmuth M, Crosby AH. 2009. Lethal cystic kidney disease in Amish neonates associated with homozygous nonsense mutation of NPHP3. Am J Kid Dis 53:790-795.

Tariq M, Belmont JW, Lalani S, Smolarek T, Ware SM. 2011. SHROOM3 is a novel candidate for heterotaxy identified by whole exome sequencing. Genome Biol 12:R91. 